ally from the temples, we shall most assuredly do more harm than good. Whichever of these remedies may be adopted as our agent, it will prove mischievous, if we rely solely upon it in the treatment of every epileptic who may come before us. Yet either of these remedies may prove successful in some one especial instance. Turpentine has been of great service; the cotyledon umbilicus, introduced to the profession in such a judicious manner by Mr. Salter, of Poole, is a valuable drug; and the "sumbul" of Dr. Granville will, I think, prove advantageous to those deplorable cases of paralysis and epilepsy which seem to arise from excessive sensual indulgence. It is the high mission of rational medicine-indeed it is its distinguishing characteristic-to treat each case according to its respective peculiarity, uninfluenced by any passing fashion, whatever that fashion may be, whether it find its exponent in a globule of dust, or in the gaudy saloons and cold fountains of a Hydropathic Symposium.

My task is now done. I am deeply sensible of its many imperfections, but its highest aim has been to elicit information, and to show by a feeble example, how readily a small part of each individual's experience may be made conducive to the general good. Perhaps I may be permitted to add, that the last case related, suggests to us the propriety of extreme caution in drawing inferences from isolated cases, especially as regards therapeutics. Had my poor patient been mesmerised on the day preceding the inflammatory attack, or had she swallowed some homœopathic globules of œnanthe crocata, stramonium, hydrocyanic acid, or any other drug said to excite convulsive disease, (similia similibus curantur,) would not the disciples of Mesmer, or Hahnemann, at once have inferred, and proclaimed-yes, proclaimed ! through all the saloons of fashionable gossip, that their " passes," or their "glo. bules," had cured the epilepsy, and that the pulmonary disease was an accidental sequence, having no influence whatever upon the former malady? Let us avoid this vice of empiricism : and, being regardless alike of the shining allurements of dishonest gain, or the false glare of a fickle popularity, let us walk together with brotherly love in that narrow but bright path of philosophic induction, which Harvey, and Hunter, and Jenner have trodden before us, and there will remain for us the happy consciousness of duties faithfully performed, and the well-founded conviction, that the talents respectively committed to us have been employed, and employed only, in those high purposes for which they were originally bestowed.

\section{A CASE OF}

\section{POISONING WITH ARSENIC ACID.}

\section{By J. SKeVingtoN, Esq., Ashbourn.}

I was sent for about nine o'clock, A.M., on the 14th of November, to attend Mrs. B., aged 53 years. On my arrival I found her vomiting violently; she com- plained of great heat and pain from the mouth to the stomach; was very faint, and had cold perspirations. I asked her what she had taken; she replied, nothing but a cup and a half of tea, containing a little carbonate of soda, and buttered toast. She complained to the servant that it tasted very peppery; and in about three minutes after drinking the tea she began to vomit. The pulse was about 120 beats in a minute, small and irregular. The skin was cold and clammy. Purging came on in about a quarter of an hour, with intense pain in the abdomen, more particularly on the left side. I ordered her into bed, and applied bottles of hot water; she soon became warm, and afterwards experienced a burning heat of the skin; the respiration was performed with difficulty; the eyes were injected with blood, and appeared as if they were leaving the sockets with intolerance of light; there was not any paralysis or exanthemata ; the tongue and fauces in many places had the appearance of being recently touched with lunar caustic ; there was great difficulty of swallowing, with violent pain in the head, and cramps of the extremities; the vomit was of a bilious character; the anus was excoriated; the urine was scanty and scalding, scarcely making any for two days; the voice was altered, and hoarseness continued for a fortnight.

The servant, a woman about 35 years of age, had taken some of the same tea, and was attacked with similar symptoms, though not quite so severe. On the third day she was taken with violent pain and swelling of the tongue, lips, and face, which continued for several days.

I gave both patients an emetic of ipecacuanha (gr. $\mathbf{x x v}$ ), and in half an hour I began with half-ounce doses of the hydrated peroxide of iron, taken every half hour. Mrs. B. took five doses, and the servant took three. The urgent symptoms of poison having subsided, they were both very ill of inflammatory fever, which, I am happy to say, gave way to the antiphlogistic treatment, and they were convalescent in a fortnight.

The analysis of the tea which remained was carefully performed by Mr. Thomas Cocker, chemist, which proves the quantity taken.

\section{A Case of Poisoning with Arsenic Acid or Arseniate of Soda.}

AT the request of $\mathrm{Mr}$. Skevington, I took charge of the remainder of the tea which had been drank by Mrs. - and her servant. There were about six ounces of it, and I tested it for arsenic.

1.-Tested the tea with blue and red litmus papers, and found it slightly acid.

2.-Prepared the fluid by adding acetic acid to coagulate the milk, \&c., boiled and filtered through paper in the usual way. When quite clear, and as free from organic and foreign matter as I could obtain it, I added the hydrosulphuret of ammonia, which produced a rich bright yellow, the sesquisulphuret of arsenic, which was soluble in ammonia, forming a nearly colourless solution. 
3.-Added the ammonio-sulphuret of copper, which produced a greenish blue precipitate; not the usual pale green-Scheele's.

4.- - Added the ammonio-nitrate of silver, which produced a reddish brown, or chocolate; not the usual colour -canary yellow, which appears with arsenious acid. The result surprised me, because it proved the presence of arsenic acid, not arsenious or common white arsenic of the shops ; repeated the experiments several times, but always with the same results.

5.-I then poured some of the tea which had been previously prepared, into a porcelain dish, added a proper quantity of hydrochloric acid, brought it to near the boiling point, put in some thin bright copper, which immediately caused a deposit of arsenic upon it.

6.-I then introduced the sulphuret of arsenic into a glass tube, with black flux, decomposed and sublimed it, which proved to a demonstration the presence of arsenic.

But the question for my consideration was,-How could arsenic acid, an article never kept in retail shops, and confined exclusively to the chemist's laboratory, have got into the tea pot? This I was surprised at, and for some time puzzled with, until I began to reflect that carbonate of soda had been put into the teapot along with the tea, and that arsenious acid was capable of uniting with it, and forming a neutral salt, the arseniate of soda, which is easily soluble in water, and this would account for its slight action on litmus paper. The brown precipitate of arseniate of silver by ammonio-nitrate of silver, and the greenish blue precipitate of arseniate of copper, in neutral solutions of arseniates, are both very characteristic tests.

Lastly.-Measured two ounces of the prepared tea, added sulphuretted hydrogen, filtered, dried, and weighed the precipitate; weighed eight grains, or about equal to six grains of white arsenic of the shops. The patient, therefore, must have taken in the eight or ten ounces of tea, about half a dram of arsenic.

Ashborne.

Thomas Cocker.

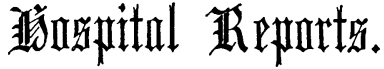

QUEEN'S HOSPITAL, BIRM I NGHAM.

CASES ADMITTED UNDER DR. DAVID NELSON

Reported under the terms proposed by the Association. By Observator.

\section{Case of Hemiplegia.}

From the frequent occurrence of paralytic cases, and the very frequent incurability of such cases, it is probable that by some persons (particularly those who have witnessed many really or assuredly incurable cases) a too general opinion has been formed, namely, that nearly all are hopeless, or, at best, only admit of slight palliation. Instances of recovery are sometimes re- corded, and to add one, of at least comparative recovery to that number, in the hope that it may contribute some degree of encouragement to treat patiently and perseveringly this truly pitiable class of suffering fellow-mortals, affords me much pleasure in reporting the following case :-

John Barrett, aged 35, of phlegmatic temperament, was admitted an in-patient of the Queen's Hospital, under Dr. Nelson, on the 20th of December, 1850. $\mathrm{He}$ was completely insensible when admitted, but, according to the statement of his friends, after taking supper on the $17 \mathrm{th}$, he went to bed in seemingly good health, not making any complaint; on the following morning he was called, and made a correct reply, but on getting up he fell down, and became insensible, remaining so until about the 21 st.

Symptoms.-Loss of sensibility and motion; paleness of countenance; pupils contracted and sluggish; slightly increased heat of the head; the mouth was drawn to the left side, and the muscles of the right side unnaturally soft; the right arm and leg were more especially incapable of any movement, but a slight degree of sensation existed, as a slight expression of countenance indicated when he was pinched; the bowels were constipated, but the urine passed involuntarily; pulse slow and full, 65 to 70 .

Diaynosis.-Apoplexy, with hemiplegia.

Indications.-To prevent effusion and inflammation, and to promote-absorption.

Treatment.-The head was shaved, and cold applied constantly; six leeches were applied behind the ears, followed by blisters; a pill of calomel and croton oil, followed by a draught of sulphate of magnesia, jalap, and senna, was administered every second hour.

2lst.-He seemed somewhat better. He took two grains of calomel every second hour, and continued the draughts. Also a seton was inserted.

22nd.--Improving a little, now having intelligence enough to open his mouth, but could not protrude his tongue, which, with his teeth, was coated with a black fur. The right arm and leg were utterly powerless. Continued the medicines, with a draught of ammonia occasionally.

23rd.-He still gradually improved, and had taken food several times. The skin was a little more sensible. Continued the medicines.

24th.-The bowels had been freely opened, but no mercurial effects had been produced. The pupils were natural. The tongue, which he drew out with his left hand, when asked to show it, was brown and dry. The hemiplegia continued, and he answered "yes" to every question. Pulse 80, softer.. Continued the medicines. 27 th. - The tongue was clean, but the other symptoms remained the same. Continued the medicines.

31st.- Seemed about the same. He continued the mercury, with an aperient draught occasionally.

January 3, 1851.-The head was cool, and the tongue clean. He had gone twice to the water-closet, with assistance; and had pronounced his own name. Pulse 88, full, and firm. Continued the medicines and'rest.

10th.-He had much improved, and could occa- 